UCRL-ID-133118

\title{
Measurement of Plutonium and other Actinide Elements at the Center for Accelerator Mass Spectrometry: A COMPARATIVE ASSESSMENTS OF COMPETING TECHNIQUES
}

J. E. McAninch

T. F. Hamilton

February 1999

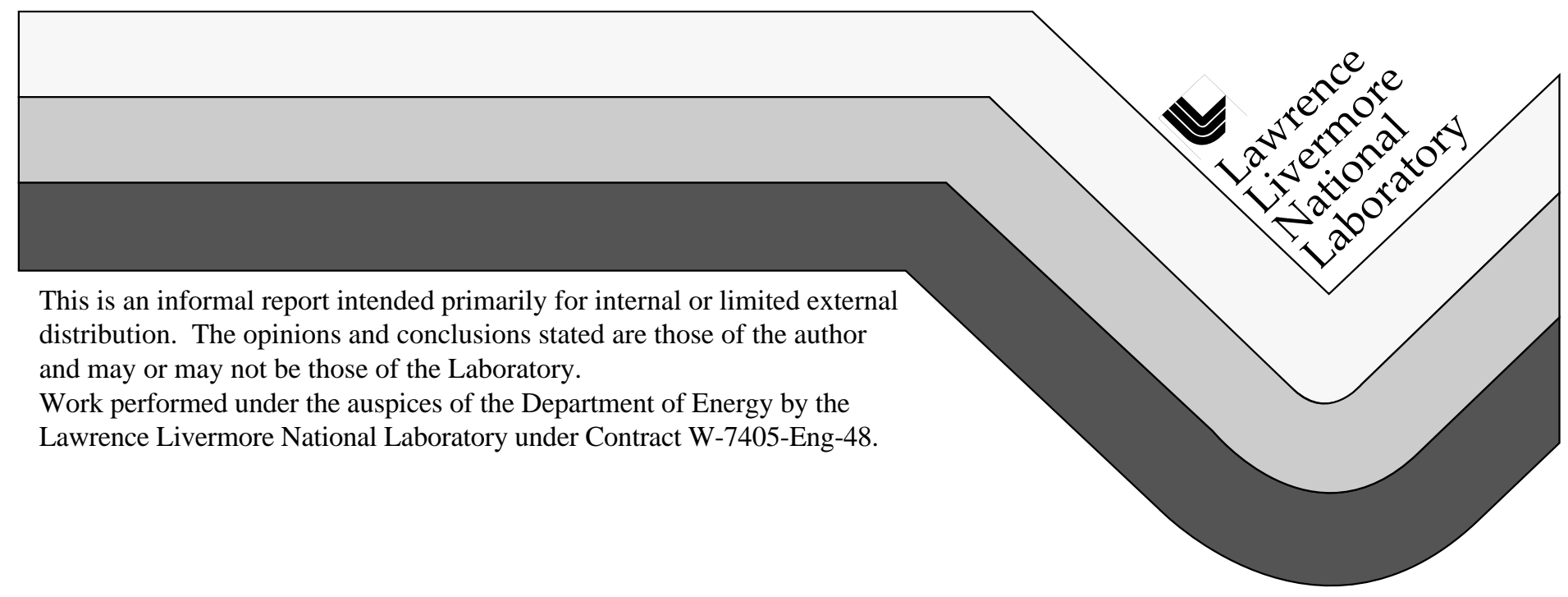




\section{DISCLAIMER}

This document was prepared as an account of work sponsored by an agency of the United States Government. Neither the United States Government nor the University of California nor any of their employees, makes any warranty, express or implied, or assumes any legal liability or responsibility for the accuracy, completeness, or usefulness of any information, apparatus, product, or process disclosed, or represents that its use would not infringe privately owned rights. Reference herein to any specific commercial product, process, or service by trade name, trademark, manufacturer, or otherwise, does not necessarily constitute or imply its endorsement, recommendation, or favoring by the United States Government or the University of California. The views and opinions of authors expressed herein do not necessarily state or reflect those of the United States Government or the University of California, and shall not be used for advertising or product endorsement purposes.

This report has been reproduced directly from the best available copy.

Available to DOE and DOE contractors from the Office of Scientific and Technical Information

P.O. Box 62, Oak Ridge, TN 37831

Prices available from (615) 576-8401, FTS 626-8401

Available to the public from the

National Technical Information Service

U.S. Department of Commerce

5285 Port Royal Rd.

Springfield, VA 22161 
Measurement of Plutonium and other Actinide Elements at the Center for Accelerator Mass Spectrometry: A COMPARATIVE ASSESSMENTS OF COMPETING TECHNIQUES

J. E. McAninch and T. F. Hamilton

Lawrence Livermore National Laboratory

Livermore, CA 94551-0808

February, 1999 
TABLE OF CONTENTS

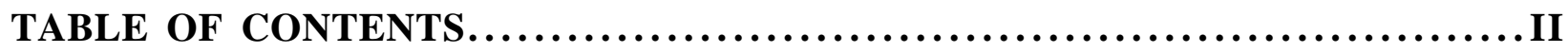

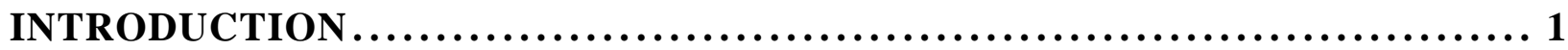

MEASUREMENT OF ACTINIDES BY ACCELERATOR MASS

SPECTROMETRY: RESULTS FROM OTHER FACILITIES................. 2

SURVEY OF COMPETING TECHNIQUES ............................. 3

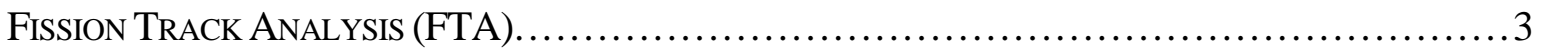

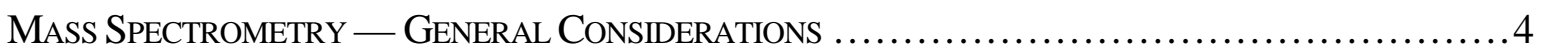

THERMAL IONIZATION MASS SPECTROMETRY (TIMS) . ..................................

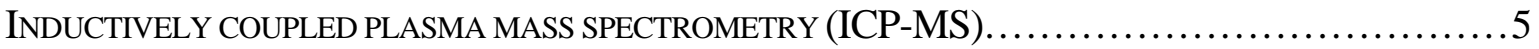

RESONANCE IONIZATION MASS SPECTROMETRY (RIMS) ................................. 8

ACCELERATOR MASS SPECTROMETRY..............................10

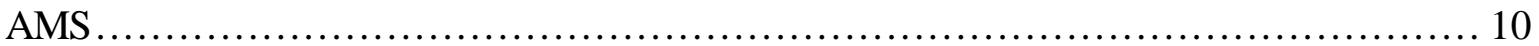

THE CENTER FOR ACCELERATOR MASS SPECTROMETRY ................................ 11

HEAVY ELEMENT BEAMLINE ....................................................... 12

FACTORS AFFECTING SENSITIVITY AND THROUGHPUT ............... 14

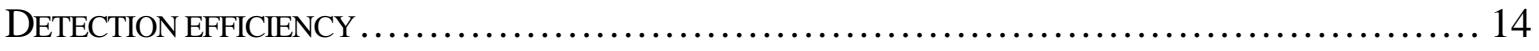

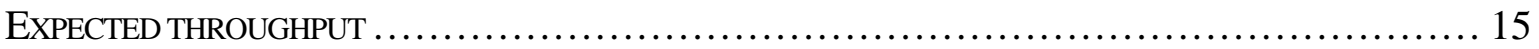

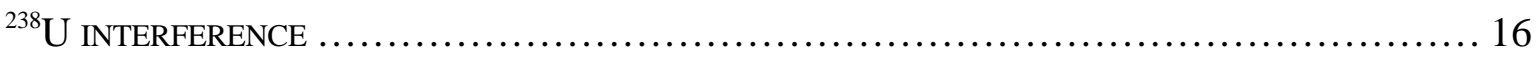

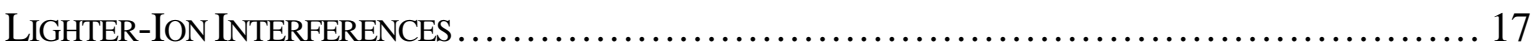

SAMPLE PREPARATION............................................. 18

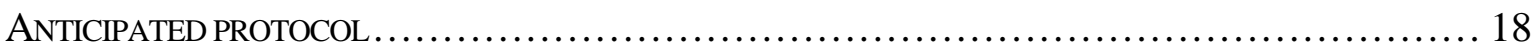

PROCESS BLANKS — STRATEGIES FOR SAMPLE PROCESSING ............................. 18

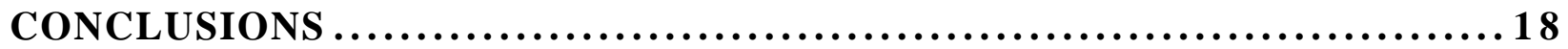

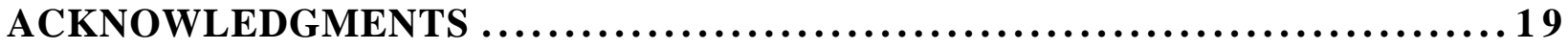

REFERENCES AND SELECTED BIBLIOGRAPHY $\ldots \ldots \ldots \ldots \ldots \ldots \ldots \ldots \ldots \ldots 19$ 


\section{INTRODUCTION}

Low-level measurements of the long-lived actinide isotopes have a number of important applications throughout the DOE complex. These include radiobioassay programs, environmental assessments, characterization of radioactive wastes, evaluation of waste storage and treatment options, environmental remediation, basic research in chemistry and geochemistry, and other specialized nonproliferation and national security applications. As an example, it has been estimated that for the next few decades more than 1 million radiochemical analyses per year will be needed in support of US efforts to remediate the legacy of radioactive waste generated by weapons production and the nuclear power industry (Crain, 1996). Traditional radiometric counting methods do not have sufficient sensitivity to address many of these requirements. There is also a growing need to evaluate and monitor exposures to DOE workers involved in decommissioning, environmental management and/or remediation of contaminated sites and facilities. Quantitative measurements based on low-level detection techniques are of particular interest in the validation of radionuclide transport models and improving radiation dosimetry/risk estimates. Quantitative data and information are required to assess the potential health-effects of exposures occurring under special conditions (e.g., resuspension/inhalation of high-specific activity particles), of inhomogeneous radiation exposure and assessment of associated dose distributions to different parts of the body/tissue, of low dose exposure, and to validate and/or develop new and improved dosimetry models.

Atom counting technology has now developed sufficiently to provide substantially better sensitivity than ionizing radiation detectors for selected longlived radionuclides. Clearly the development of a robust, high-throughput, highly sensitive actinide measurement capability based on this new technology would have broad and sustainable impact on a range of DOE initiatives. One potential measurement technique for meeting these requirements is accelerator mass spectrometry (AMS). AMS is a widely accepted analytical technique for measurement of isotopes such as ${ }^{14} \mathrm{C},{ }^{26} \mathrm{Al},{ }^{36} \mathrm{Cl}$ (Vogel et al., 1995) but has only recently been demonstrated for the quantitative detection of actinides (Fifield et al., 1996).

The Center for Accelerator Mass Spectrometry (CAMS) at the Lawrence Livermore National Laboratory (LLNL) operates the most versatile and most productive AMS instrument in the world (Roberts et al., 1996). The addition of a Heavy Ion Beamline and associated hardware for actinide detection are in an advanced stage of development. Detection limits for actinide elements are expected to be on the order of $1 \times 10^{6}$ atoms $(\sim 0.5 \mathrm{fg})$ or lower with an initial measurement capacity of a few hundred samples per year. The ultimate detection sensitivity is expected to be $\sim 1 \times 10^{5}$ atoms.

Here we provide a review of non-conventional measurement techniques-including AMS-for the determination of low-levels of ${ }^{239} \mathrm{Pu}$ and 
other actinide elements in environmental samples. We include a discussion of potential measurement interferences and sample preparation requirements for the different techniques, and outline our proposed AMS system design and strategic approach for the development of low-level actinide detection capability at CAMS.

\section{Measurement of Actinides by Accelerator Mass Spectrometry: results from OTHER FACILITIES}

The feasibility of measuring actinides by AMS was demonstrated by researchers from the Australian National University (ANU) and the University of Manchester using a 14 MV accelerator (Fifield et al., 1997). This initial study was undertaken to determine the feasibility of applying quantitative AMS to determine Pu isotopes at levels below those obtainable by existing techniques. The combined activity of ${ }^{239} \mathrm{Pu}$ and ${ }^{240} \mathrm{Pu}$ in a series of soil extracts were found to be in general agreement with results obtained by alpha-spectrometry. The reported detection limit for ${ }^{239} \mathrm{Pu}$ and ${ }^{240} \mathrm{Pu}$ of $1 \times 10^{6}$ atoms per sample is at least two orders of magnitude lower than for alpha counting. More recently, the group at ANU/Manchester have for the first time demonstrated the feasibility of using AMS for the quantitative detection of ${ }^{237} \mathrm{~Np}$, and compare the ion formation probabilities, backgrounds and transmission rates with those of the other actinides including plutonium (Fifield et al., 1997). Again, the results of analyses of environmental samples compared to those performed by ICP-MS were in reasonable agreement.

The studies conducted at ANU/Manchester answer some important questions and illuminate several issues relevant to measurements at CAMS. To summarize, they:

- Demonstrated quantification and reproducibility for plutonium and neptunium measurements using AMS.

- Demonstrated that high accelerator energies were not required (measurements were performed at 3.5 and $5.3 \mathrm{MV}$ ).

- Performed these measurements with no electrostatic filtering elements in either the injection or high-energy spectrometers.

- Identified uranium as a limiting interference to AMS measurements of ${ }^{239} \mathrm{Pu}$ and ${ }^{240} \mathrm{Pu}$, elucidated the primary mechanism for this interference, and demonstrated that uranium could be reduced to necessary levels by the sample purification procedure.

- Observed low memory effect, so that it should be possible to consecutively measure samples varying in activity by $4-5$ orders of magnitude.

- Developed an appropriate sample matrix (iron oxide) and showed that no interferences or backgrounds resulted from that matrix.

- Determined the optimum ion for injection into the accelerator $\left(\mathrm{PuO}^{-}\right)$, and measured the efficiency for conversion of sample atoms to negative ions $(0.3 \%$ in the case of $\mathrm{UO}^{-}$). 
- Demonstrated an effective detector for ion counting and identification (a gas ionization detector modified to improve resolution for heavy ions).

Since publication of these initial findings, the ANU/Manchester group has successfully applied their methods to a large number of measurements of ${ }^{239} \mathrm{Pu} /{ }^{240} \mathrm{Pu}$ in environmental samples (Day, 1998).

\section{SURVEY OF COMPETING TECHNIQUES}

A number of non-conventional techniques exist for the low-level determination of actinide elements in the environment. A comparison of the relative detection limits for ${ }^{239} \mathrm{Pu}$ are shown in Table 1.

\section{Fission Track Analysis (FTA)}

Fission track analysis uses thermal neutron induced fission to detect fissionable isotopes by counting the number of defect tracks produced in a quartz or plastic plate by the high energy fission products. For ${ }^{239} \mathrm{Pu}$ determination samples are typically wet ashed to remove organics and water, chemically treated by ion chromatrography to separate plutonium isotopes from any interferences, and the resulting eluant deposited on a quartz slide. The slides are then exposed to a thermal neutron source, inducing plutonium fission. Approximately $90 \%$ of the fission energy is released as kinetic energy of fission fragments. The passage of these heavily ionizing particles through quartz (or other suitable track-etch material) causes a trail of intense damage on an atomic scale. Chemical etching of the damaged material reveals characteristic cone shaped tracks that are visible under an optical microscope. Quantification is performed by counting the tracks per slide, and converting to plutonium mass (activity) by calibration with sets of standard slides irradiated under the same conditions.

Three competing FTA measurement techniques developed by the University of Utah Environmental, Radiation and Toxicology Laboratory (ERTL), the Brookhaven National Laboratory (BNL), and the Department of Radiation Physics (Lund University, Sweden) are currently used to determine ${ }^{239} \mathrm{Pu}$ in human urine (Krahenbuhl \& Slaughter, 1998). The reported detection limits at each of these laboratories are $\sim 1 \times 10^{6}$ atoms, $2-3 \times 10^{6}$ atoms, and $2 \times 10^{6}$ atoms, respectively. Historically fission track analysis methodology has been plagued with deficiencies in sample collection, use of less than reliable and tedious preparative techniques, low chemical yields, contamination, and inaccurate quantification. More recent reports suggest that improvements in process methodology, and adoption of a more rigorous approach to data reduction and quality assurance can significantly increase the reliability and accuracy of FTA (Krahenbuhl \& Slaughter, 1998). One of the inherent disadvantages of FTA lies in the fact that tracks created by fission fragments are not directly attributable to any particular fissile contaminant. For example, the fission cross-section of ${ }^{235} \mathrm{U}$ is comparable to that of ${ }^{239} \mathrm{Pu}$. Uranium is ubiquitous in the environment and typical background concentrations in urine range from 6 to 30 
ng L ${ }^{-1}$ (Kaspas et al., 1996). Any uranium remaining after sample preparation (or associated with the detector material) can produce tracks from fissioning ${ }^{235} \mathrm{U}$ and may increase the ${ }^{239} \mathrm{Pu}$ background count on the FTA plates to intolerable levels. Adequate analytical separation schemes with reported levels of discrimination against uranium of $>10^{8}$ are available for low-level determination of ${ }^{239} \mathrm{Pu}$ (Wrenn et al., 1994). However, high quality measurements appear to be limited to those laboratories that pay special attention to quality assurance measures. Critical stages of the technique are performed by well trained personnel in a dust free environment (i.e., Class 100 laminar hood), uranium free reagents are used and acids purified by sub-boiling distillation. The need for these additional analytical controls, the high cost of subsequent track detection/data reduction, and apparent lack of reliability of fission track analysis should be carefully considered in any comparative analysis.

\section{Mass Spectrometry - General Considerations}

For the low-level analysis of long-lived radionuclides, mass spectrometric atom counting techniques provide the best sensitivity. Atom counting techniques offer three significant advantages over conventional ionizing radiation detectors:

1) A higher detection sensitivity and shorter measurement time-typically on the order of minutes to hours.

2) Detection sensitivity does not depend on the energy or type of radiation, allowing weak emitters to be detected with the same efficiency as high energy emitters.

3) Atom counting techniques are free from interferences associated with the decay emissions of other radionuclides that may be present in the sample. As a consequence, detection sensitivity does not depend on the total activity present in the sample.

Atom counting techniques applied to low-level determination of long-lived radionuclides include inductively coupled plasma mass spectrometry (ICP-MS), thermal ionization mass spectrometry (TIMS), laser resonance ion ionization mass spectrometry (RIMS) and accelerator mass spectrometry (AMS).

The two major considerations in mass spectrometric techniques are sample preparation and interferences from molecular and atomic isobars. Samples must be prepared in a form and size that provide efficient ion production, and matrix elements should be removed if they degrade the performance of the system. Adjustments to the sample form may also be necessary in order to reduce crosscontamination between consecutive samples (i.e., memory effects). Finally, sample preparation must be used to minimize the level of isobaric interference in the sample. The type of interferences present and the ability to remove or account for them in the spectrometer differ between techniques and isotopes. 


\section{Thermal Ionization Mass Spectrometry (TIMS)}

The most sensitive proven method for detection of low-levels of actinides is TIMS (Perrin et al., 1985; Buesseler \& Halverson, 1987; McCormick, 1992). TIMS has a long history of producing sensitive, high precision isotope ratio measurements of long-lived actinides. Typically, a few $\mu \mathrm{L}$ of a purified sample solution containing the analyte of interest is placed onto a Rhenium filament and dried. The filament is then heated in a controlled manner to ionize the sample. The sensitivity and precision of the measurements depend on the specific type of ion source and spectrometer employed. In general, the ionization efficiency of TIMS is much higher than that of ICP-MS, allowing significantly smaller quantities of material to be analyzed.

The main disadvantage of TIMS is that measurement times are typically one to several hours per sample. Consequently, only a few samples can be measured per day. A further disadvantage is that filament preparation is very time-consuming and requires careful attention. Also, additives are often used to enhance the ionization efficiency. Despite these difficulties and the associated high cost, studies involving several hundred TIMS analyses of environmental sample have been reported (Taylor et al., 1998)

Buesseler, et al. (1987) measured an average concentration of $(0.17 \pm 0.02) \times 10^{6}$ atoms ${ }^{239} \mathrm{Pu}$ in a set of 5 water samples (3-5 L. each), implying a baseline detection limit of $\sim 0.06 \times 10^{6}$ atoms ${ }^{239} \mathrm{Pu}$ per sample. In the same study, the measurement background for 3 sediment samples $(1-10 \mathrm{~g})$ was $(1.1-2.6) \times 10^{6}$ atoms ${ }^{239} \mathrm{Pu}$.

\section{Inductively coupled plasma mass spectrometry (ICP-MS)}

Inductively coupled plasma mass spectrometry has the sensitivity to detect lowlevels of long-lived radionuclides (Crain, 1996; Momoshima et al., 1997; Lee et al., 1995). Typically, an aqueous sample containing the analyte of interest is introduced into a high temperature Argon plasma $\left(6000-7000^{\circ} \mathrm{K}\right)$ - usually in the form of an aerosol. The sample is ionized and the resulting ions accelerated to a few tens of kilovolts, analyzed in a quadrupole or magnetic sector mass spectrometer, and the individual ions counted. Sensitivity and precision depend on the sample introduction technique, the type of spectrometer and the mode of data acquisition. Mass scanning and peak jumping modes allow multielement, isotope ratio and/or isotope dilution measurements to be made. ICP-MS also allows relatively fast measurements (minutes per sample) to be performed with minimal downtime between samples.

Typical ICP-MS systems use a quadrupole mass spectrometer (ICPMS-Q) with pneumatic sample injection (Roth et al., 1996; Alvarado et al., 1996; Lorder et al., 1996; Karpas et al., 1996; Wollenweber et al., 1997). More efficient sample introduction methods include ultrasonic nebulizers (USN) (Sumiya et al., 1994; Crain \& Alvarado, 1994; Crain et al., 1995; Chiappini et al., 1996) and electrothermal vaporization units (ETV) (Alvarado \& Erickson, 1996; Scott et al., 1991; Baxter et al., 1995; Bailey et al., 1993). Coupling of other sample definition techniques, such as ion 
chromatography (IC) (Barrero Moreno et al., 1997), have also been used for on-line chemical processing and speciation studies. More recently, ICP-MS systems employing double focusing mass spectrometers (ICPMS-DF) have become available (Wollenweber et al., 1997; Moens \& Jakubowski, 1998; Kim et al., 1991; Kerl et al., 1997).

Two of the most difficult actinide isotopes to measure by ICP-MS at low fg levels are ${ }^{238} \mathrm{U}$ and ${ }^{239} \mathrm{Pu}$. The main problem in low-level uranium measurements is the relatively high natural abundance of uranium in samples and/or process chemicals (Wollenweber et al., 1997). Ultrapure reagents have uranium levels of 5-50 fg U per $\mathrm{mL}$ reagent although detection sensitivities below $10 \mathrm{fg} U$ per $\mathrm{mL}$ sample have been reported. Uranium is also a limiting factor for low-level measurements of ${ }^{239} \mathrm{Pu}$ by ICP-MS because formation of ${ }^{238} \mathrm{U}^{1} \mathrm{H}^{+}$ions in the ICP torch gives rise to an isobaric interference at mass 239 (Crain, 1996). The formation probability for uranium hydride $\left({ }^{238} \mathrm{U}^{1} \mathrm{H}^{+} /{ }^{238} \mathrm{U}^{+}\right)$is $\sim 1-10 \times 10^{-5}$, depending on the torch conditions and type of nebulizer used (Crain 1996; Sumiya et al., 1994; Chiappini et al., 1996; Scott et al., 1991). Thorium hydride formation also causes an isobaric interference on ICP-MS measurements of ${ }^{233} \mathrm{U}$ (Sumiya et al., 1994), and similarly, thorium carbide could present a limiting interference for ${ }^{244} \mathrm{Pu}$ measurements.

Electrothermal vaporization can enhance ICP-MS detection limits for some analytes. Sample introduction and handling are similar to that used in graphite furnace atomic absorption spectrometry (GFAAS), and the two methods share the same advantages and disadvantages. Ten to $50 \mu \mathrm{L}$ aqueous samples are injected into a graphite furnace, and through a series of temperature ramps, the sample is evaporated to dryness, ashed to remove organics, vaporized at high temperature and the analyte of interest transported to the ICP in an argon gas flow. The advantages of this sample introduction technique are high analyte transport efficiency and utilization of very small sample volumes; reduction of polyatomic ion interferences, reduction of oxide formation of the analyte, plasma gas, and matrix components; acceptance of a variety of sample matrices directly into the furnace; reduction of interferences through selective vaporization in the ramping sequence; and the possibility of using matrix modifiers to enhance atomization of the analyte (Alvarado \& Erickson, 1996). Signal to background ratios may also be improved since data acquisition is compressed into just a few seconds.

In practice, use of ETV as a sample introduction technique appears to be a poor choice-at least in the case of low-level actinide measurements. ETV shows poor reproducibility and stability, matrix effects can cause large variations in atomization efficiency, and sample-to-sample memory affects are large (Alvarado \& Erickson, 1996; Chiappini et al., 1996). Also, the transient nature of the signal is a significant hindrance in system tuning and data acquisition. Scott et al., (1991) reported a detection limit of $4 \times 10^{7}$ atoms for ${ }^{239} \mathrm{Pu}$ by ETV-ICPMS-Q with mass scanning, and $2.5 \times 10^{6}$ atoms using single ion monitoring. Single ion mode measurements do not allow simultaneous measurement of the isotope dilution spike, therefore significantly deteriorating the accuracy of the measurement. Baxter (referenced as a 
personal communication in Scott et al., 1991) has claimed a ${ }^{239} \mathrm{Pu}$ detection limit of $\sim 0.6 \times 10^{6}$ atoms using ETV-ICP-MS, but this may have been spurious as no subsequent reports of such low-levels of sensitivity have occurred in the literature. It should also be noted that ETV does not provide any improvement on the uranium hydride interference on ${ }^{239} \mathrm{Pu}$, since $\mathrm{UH}^{+}$formation takes place in the ICP.

The primary distinguishing feature of modern, double focusing ICP-MS units is the high resolution that can be obtained. Commercial instruments have a maximum resolution of 7500-12000 (Moens \& Jakubowski, 1998), compared to the typical quadrupole resolution of 300-400. As with ETV, however, this distinguishing feature does not help address the primary limitation of low-level ${ }^{239} \mathrm{Pu}$ measurements by ICP-MS, ie., uranium hydride interferences. To separate ${ }^{238} \mathrm{U}^{1} \mathrm{H}^{+}$from ${ }^{239} \mathrm{Pu}^{+}$would require an instrument with resolution of 37000 (Crain, 1996), well beyond the capabilities of presently available commercial systems. Furthermore, the transmission efficiency of these instruments in the high resolution mode is very low. High resolution mode is only applicable for precision isotope ratio measurements or measurement of certain isotopes with large interferences at relatively high concentrations (Moens \& Jakubowski, 1998). For applications requiring high efficiency (such as fg levels of ${ }^{239} \mathrm{Pu}$ ), the instrument is normally operated in the low resolution mode (resolution 300-400, the same as quadrupole systems) (Crain, 1996; Wollenweber et al., 1997; Moens \& Jakubowski, 1998; Kerl et al., 1997). Therefore, a double focusing mass spectrometer does not offer improved sensitivity for ${ }^{239} \mathrm{Pu}$ measurements.

A second potential advantage of double focusing ICP-MS systems is that background noise rates are typically much lower than for quadrupole instruments. This is because the noise rate in a quadrupole mass spectrometer is dominated by line-of-sight photons from the ICP reaching the ion detector. In a double focusing system, there are no line-of-sight photons reaching the detector, and consequently, the background noise is greatly reduced. However, this advantage does appear to have been translated directly in terms of reports of lower detection limits for actinides, including ${ }^{239} \mathrm{Pu}$.

A full evaluation and description of ICP-MS parameters and associated detection limits for measurement of ${ }^{239} \mathrm{Pu}$ in environmental samples can be found in Chiappini et al. (1996). In this study, a relatively standard quadrupole ICP-MS system (PlasmaQuad 2+, with 'S' option sampler-skimmer interface) was used to measure ${ }^{239} \mathrm{Pu}$ and ${ }^{240} \mathrm{Pu}$ in sediments and fish samples, and the results compared to alpha particle counting. These authors also compared instrumental detection limits for three different nebulizer configurations, and found that the best results, based on background noise and ${ }^{238} \mathrm{U}^{1} \mathrm{H}^{+}$formation, were obtained with a high-efficiency desolvating nebulizer (Fisons 'Mistral'). Relevant parameters in the optimum configuration were:

- uranium hydride production:

- sensitivity:

${ }^{238} \mathrm{U}^{1} \mathrm{H}^{+} /{ }^{238} \mathrm{U}^{+}=1.1 \times 10^{-5}$
1.5 counts s $\mathrm{s}^{-1}$ for $1 \mathrm{fg}{ }^{238} \mathrm{U} / \mathrm{mL}$ 
- background noise:

- memory effect:

- sample uptake rate:

- instrumental detection limit: $\sim 3 \times 10^{6}$ atoms for ${ }^{239} \mathrm{Pu},{ }^{240} \mathrm{Pu},{ }^{237} \mathrm{~Np}$ and others

In applying this method to their environmental samples, they found that their sample preparation procedure was sufficient to reduce uranium in the final measurement aliquot to $\sim 150 \mathrm{pg} \mathrm{U} \mathrm{mL}{ }^{-1}$. The resulting hydride interference increased the detection limit for ${ }^{239} \mathrm{Pu}$ to $\sim 6 \times 10^{6}$ atoms. In closing, they report that this method is now routinely applied in their laboratory to a number of long-lived radionuclides in environmental samples.

The results of this work have implications both for the ultimate limits of detection for ICP-MS using any instrument, and for AMS measurements as discussed below.

\section{Resonance Ionization Mass Spectrometry (RIMS)}

RIMS instruments employ highly tuned lasers to ionize atoms in a multi-step process that provides a high degree of elemental and isotopic selectivity. RIMS requires an atomic vapor of the analyte for photoionization. Conventional sample preparation techniques are used for low-level plutonium measurements but some additional sample processing is required to produce a two-layer filament suitable for electrothermal vaporization (Eberhardt et al., 1994). The purified sample is first fumed with sulfuric acid, then dissolved in ammonium sulfate matrix, from which plutonium isotopes are electrolytically deposited onto a tantalum backing. A thin titanium layer is then deposited over the sample by sputtering. This filament is then heated, converting the hydroxide to plutonium oxide. During analysis, heating of the filament causes the plutonium to diffuse through the titanium layer, reducing it to the metallic state, and producing an atomic plutonium vapor for ionization. The RIMS setup consists of three tuneable dye lasers which photoionize the plutonium through a three-step, three-color resonance excitation process. The resulting ions are then analyzed in a time-of-flight mass spectrometer.

RIMS measurements of plutonium isotopes in environmental and urine samples have been reported by Erdmann et al. (1997) at Universität Mainz. This group has been exploring RIMS or the ultratrace detection of plutonium and other long-lived isotopes for several years (Eberhardt et al., 1997; Ruster et al., 1989; Urban et al., 1992; Erdmann et al., 1994). The reported detection limit for ${ }^{239} \mathrm{Pu}$ measurements are on the order of 1-2 $\times 10^{6}$ atoms per sample. 
Table 1. Selected literature on low level actinide measurements. When only a concentration limit was quoted, and sample volume was not given, a minimum volume was estimated from the operating conditions, or $1 \mathrm{~mL}$ assumed. Isotopes other than ${ }^{239} \mathrm{Pu}$ are shown in parentheses.

\begin{tabular}{|c|c|c|c|c|c|}
\hline Reference/Yr & Method & Isotope & Sample & $\begin{array}{l}\text { LLD } \\
10^{6} \\
\text { atoms }\end{array}$ & Comments \\
\hline Crain 1994 & USN-ICPMS-Q & \multicolumn{4}{|c|}{ studied ${ }^{238} \mathrm{U}^{1} \mathrm{H}^{+} /{ }^{238} \mathrm{U}^{+}$formation in ICP source $\left(=1-3 \times 10^{-5}\right)$} \\
\hline $\begin{array}{l}\text { Barrero Moreno } \\
1997\end{array}$ & IC-ICPMS-Q & $\begin{array}{c}{ }^{239} \mathrm{Pu} \\
\left({ }^{237} \mathrm{~Np}\right)\end{array}$ & U fuel pellets & $\begin{array}{l}10000 \\
(3000)\end{array}$ & $\begin{array}{l}\text { ion } \\
\text { chromatography- } \\
\text { ICP-MS }\end{array}$ \\
\hline Alvarado $1996 \mathrm{~b}$ & PN-ICPMS-Q & $\left({ }^{238} \mathrm{U}\right)$ & leaves & $(4000)$ & \\
\hline Lorber 1996 & ICPMS-Q & $\left({ }^{238} \mathrm{U}\right)$ & urine, serum & $(3000)$ & \\
\hline Roth 1996 & PN-ICPMS-Q & $\left({ }^{232} \mathrm{Th}\right)$ & urine & $(3000)$ & \\
\hline $\begin{array}{l}\text { Momoshima } \\
1997\end{array}$ & PN-ICPMS-Q & ${ }^{239} \mathrm{Pu}$ & $\begin{array}{l}\text { soils, pine } \\
\text { needles }\end{array}$ & 100 & \\
\hline $\begin{array}{l}\text { Wollenweber } \\
1997\end{array}$ & USN-ICPMS-DF & $\left({ }^{238} \mathrm{U}\right)$ & $\begin{array}{l}\text { high purity } \\
\text { water }\end{array}$ & $(\sim 60)$ & \\
\hline Crain 1995 & USN-ICPMS-Q & ${ }^{239} \mathrm{Pu}$ & soils & 60 & \\
\hline Lee 1995 & ICP-MS & $\left({ }^{237} \mathrm{~Np}\right)$ & artificial urine & $(30)^{\mathrm{a}}$ & intercomparison \\
\hline Sumiya 1994 & USN-ICPMS-Q & ${ }^{239} \mathrm{Pu}$ & soils & 20 & \\
\hline Bailey 1993 & ETV-ICPMS-Q & $\left({ }^{238} \mathrm{U}\right)$ & rocks & $(\sim 10)$ & \\
\hline Kim 1991 & USN-ICPMS-DF & $\begin{array}{l}{ }^{239} \mathrm{Pu} \\
\left({ }^{240} \mathrm{Pu}\right)\end{array}$ & $\begin{array}{l}\text { instrument } \\
\text { blanks }\end{array}$ & $\begin{array}{l}10 \\
(1)\end{array}$ & PN and USN \\
\hline Crain 1996 & USN-ICPMS-DF & ${ }^{239} \mathrm{Pu}$ & & $\sim 10$ & review article \\
\hline Alvarado 1996a & ETV-ICPMS-Q & $\left({ }^{238} \mathrm{U}\right)$ & water & (7) & \\
\hline Chiappini 1996 & ICPMS-Q & $\begin{array}{c}{ }^{239} \mathrm{Pu} \\
\left({ }^{237} \mathrm{~Np}\right)\end{array}$ & $\begin{array}{c}\text { soils } \\
\text { (inst. blanks) }\end{array}$ & $\begin{array}{c}7 \\
(3)\end{array}$ & $\begin{array}{l}\text { desolvating } \\
\text { nebulizer }\end{array}$ \\
\hline Kerl 1997 & ICPMS-DF & $\left({ }^{238} \mathrm{U}\right)$ & $\begin{array}{l}\text { high purity } \\
\text { water }\end{array}$ & $(\sim 6)$ & various nebulizers \\
\hline Scott 1991 & ETV-ICPMS-Q & ${ }^{239} \mathrm{Pu}$ & $\begin{array}{l}\text { instrument } \\
\text { limit }\end{array}$ & $\begin{array}{l}40 \\
2.5\end{array}$ & $\begin{array}{l}\text { mass scan mode } \\
\text { single ion mode }\end{array}$ \\
\hline Baxter 1995 & ETV-ICPMS-Q & ${ }^{239} \mathrm{Pu}$ & urine & $0.6^{\mathrm{c}}$ & expected sensitivity \\
\hline Sun 1995 & FTA & ${ }^{239} \mathrm{Pu}$ & urine & 3 & \\
\hline Erdmann 1997 & RIMS & ${ }^{239} \mathrm{Pu}$ & urine, soils & $\sim 2$ & \\
\hline Fifield 1997 & AMS & $\begin{array}{c}{ }^{239} \mathrm{Pu} \\
\left({ }^{237} \mathrm{~Np}\right)\end{array}$ & $\begin{array}{l}\text { instrument } \\
\text { blanks }\end{array}$ & $\begin{array}{c}0.4 \\
(<1)\end{array}$ & \\
\hline Buesseler 1987 & TIMS & ${ }^{239} \mathrm{Pu}$ & $\begin{array}{l}\text { pore waters } \\
\text { sediments }\end{array}$ & $\begin{array}{l}<0.1 \\
\sim 2.5\end{array}$ & \\
\hline
\end{tabular}

\footnotetext{
a Value listed is lowest minimum detectable concentration reported for the techniques and laboratories included in the intercomparison.

${ }^{\mathrm{b}}$ Single ion mode does not provide for measurement isotope dilution spike, significantly limiting precision of the method.

${ }^{c}$ Anticipated value for single ion mode. Value listed was referenced by "private communication".
} 


\section{Accelerator Mass Spectrometry}

\section{AMS}

Accelerator mass spectrometry is an ultra-sensitive technique for the detection of rare isotopes, typically those long-lived radioisotopes that cannot readily be detected by decay counting. AMS is now routinely applied to the detection of rare isotopes in a wide range of fields. Often 50-100 samples per day are measured, and a precision of $10 \%$ or better can be achieved for samples containing $\sim 1 \times 10^{6}$ atoms of the isotope. Rare to stable isotope ratios can be as low as $10^{-14}-10^{-15}$.

Samples are prepared as a solid matrix, consisting of an appropriate compound of the element of interest. A metallic carrier such as silver is often included to help stabilize the sample in the ion source. Typically the final prepared sample form consists of $\sim 1 \mathrm{mg}$ of material, including metallic carrier, packed into an appropriate target holder. The sample is ionized using a cesium sputter ion source, and the resulting negative ions are injected into a tandem Van de Graaff accelerator. Electrons are stripped from the ions in the accelerator, and any molecular ions are

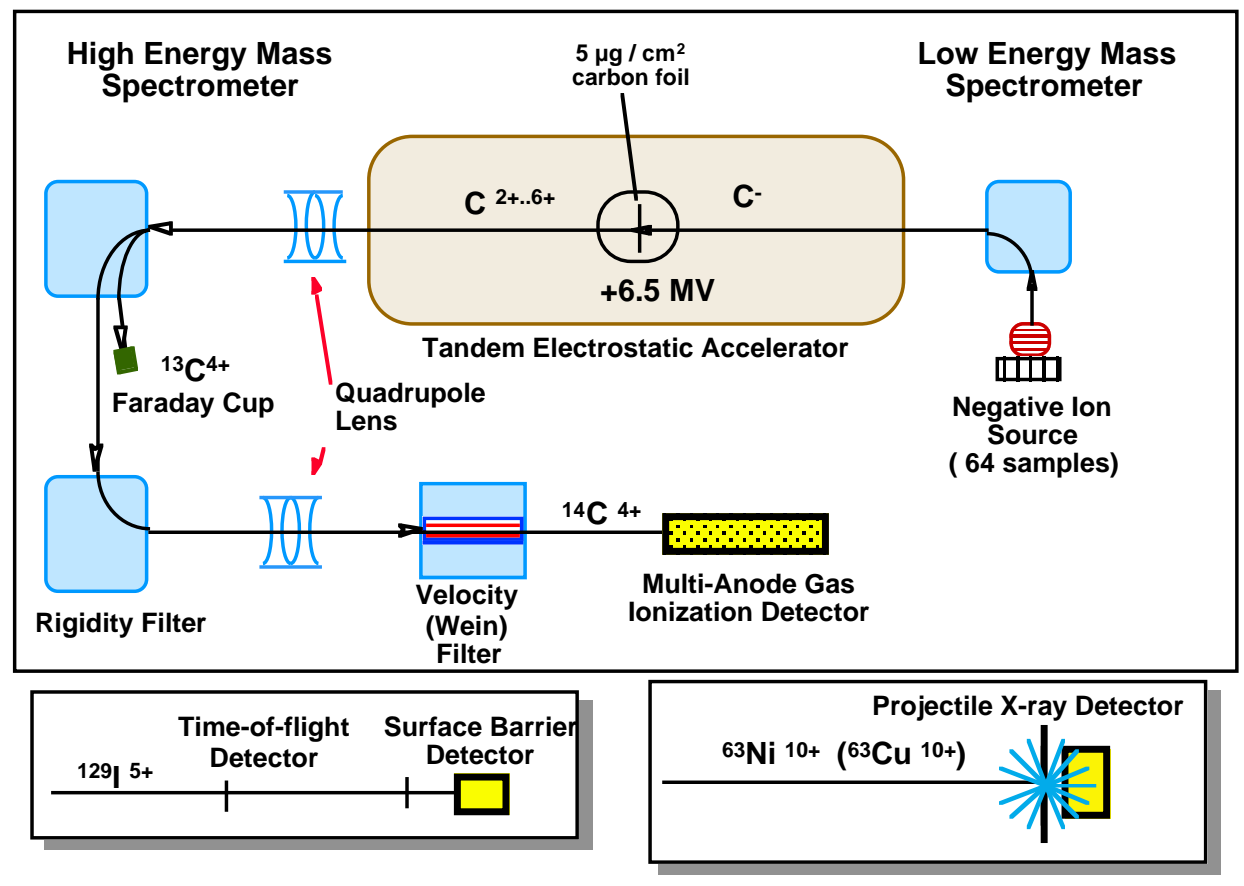

Figure 1. Schematic of the basic LLNL accelerator mass spectrometer shows the major components used to obtain part in $10^{15}$ sensitivity in detecting rare isotopes. Shown is the configuration for ${ }^{14} \mathrm{C}$ measurements, in which a gas ionization counter is used for ion identification and counting. Other detectors are available for the rejection of certain types of interferences, depending on the isotope being measured. 
broken up. The ions exit the accelerator as multiply-charged positive atomic ions with 1-200 MeV of energy, depending on the ion and accelerator. Following postaccelerator analysis in the high-energy mass spectrometer, the rare ions are counted individually in a particle detector, typically a gas ionization detector. The stable and rare ion currents are measured simultaneously or quasi-simultaneously. The result is a measurement of the rare-to-stable isotope ratio. Comparison to standards yields the absolute mass of rare isotope in the sample.

In the case of long-lived actinides, isotope dilution spikes are used in place of a stable isotope, and the analyte-to-spike counts measured. Again, comparison to standards yield the absolute mass of the analyte isotope in the sample.

\section{The Center for Accelerator Mass Spectrometry}

The Center for Accelerator Mass Spectrometry (CAMS) operates a 10 MV FN tandem Van de Graaff accelerator at Lawrence Livermore National Laboratory. Accelerator mass spectrometry operations began in 1989 and initially accounted for approximately $20 \%$ of the accelerator usage. At present nearly $100 \%$ of the usage is devoted to AMS measurements and development, making use of $70-80 \%$ of the available accelerator time. Routine measurement capability includes ${ }^{3} \mathrm{H},{ }^{10} \mathrm{Be},{ }^{14} \mathrm{C}$, ${ }^{26} \mathrm{Al},{ }^{36} \mathrm{Cl},{ }^{41} \mathrm{Ca}$, and ${ }^{129} \mathrm{I}$. Other isotopes including ${ }^{63} \mathrm{Ni}$ and ${ }^{99} \mathrm{Tc}$ are currently under development. More than 20,000 analyses were performed during FY97 (Table 2). The present CAMS spectrometer is shown in Figure 1.

CAMS measurement activities support internal and collaborative research in

Table 2. AMS measurements at CAMS during FY97.

\begin{tabular}{lcccc}
\hline isotope & stable ion current & background & accuracy & samples \\
\hline${ }^{14} \mathrm{C}$ Biomed & $100 \mu \mathrm{A}^{12} \mathrm{C}-$ & $1 \times 10^{-14}$ & $2 \%$ & 6,300 \\
${ }^{14} \mathrm{C}$ Natural & $120 \mu \mathrm{A}^{12} \mathrm{C}^{-}$ & $45 \mathrm{ka}$ & $0.7 \%$ & 10,150 \\
${ }^{3} \mathrm{H}$ & $15 \mu \mathrm{A}^{1} \mathrm{H}-$ & $2 \times 10^{-15}$ & $5-10 \%$ & 400 \\
${ }^{10} \mathrm{Be}$ & $2-4 \mu \mathrm{A}^{9} \mathrm{BeO}^{-}$ & $5-15 \times 10^{-15}$ & $2-3 \%$ & 1,400 \\
${ }^{26} \mathrm{Al}$ & $0.5-1 \mu \mathrm{A}^{27} \mathrm{Al}^{-}$ & $1-2 \times 10^{-15}$ & $3-4 \%$ & 900 \\
${ }^{36} \mathrm{Cl}$ & $20-40 \mu \mathrm{A}^{37} \mathrm{Cl}^{-}$ & $3 \times 10^{-15}$ & $3 \%$ & 700 \\
${ }^{41} \mathrm{Ca}$ & $500 \mathrm{nA}^{40} \mathrm{CaF}^{-}$ & $3 \times 10^{-13}$ & $5 \%$ & 300 \\
${ }^{129} \mathrm{I}$ & $25 \mu \mathrm{A}{ }^{129} \mathrm{I}^{-}$ & $5 \times 10^{-14}$ & $5 \%$ & 350 \\
${ }^{63} \mathrm{Ni}$ & $25 \mu \mathrm{A}^{58} \mathrm{Ni}^{-13}$ & $3 \times 10^{-13}$ & $5 \%$ & development \\
${ }^{59} \mathrm{Ni}$ & $25 \mu \mathrm{A}^{58} \mathrm{Ni}$ & $3 \times 10^{-12}$ & $5 \%$ & development \\
${ }^{99} \mathrm{Tc}$ & - & - & - & development \\
& & & Total: & 20,500 \\
\hline
\end{tabular}


archaeology, bioscience, environmental science, global climate change, geoscience, hydrology, materials science, risk assessment and nonproliferation and national security, and provides measurement services to a broad range of DOE and non-DOE customers. Present CAMS development activities include new application areas for AMS, addition of new isotope measurement capabilities, and installation of additional accelerators for bioscience applications and nuclear microscopy. CAMS is the recognized world leader in bioscience applications of AMS. A regular program of facility upgrades including ion source improvements and enhancement of the data acquisition systems produces continued increases in system throughput, capacity, reliability and precision.

The CAMS facility has been optimized for maximum throughput and reliability. Downtime, including scheduled maintenance of the accelerator, is historically less than 5 days per year. Four hours per week are reserved for various facility maintenance activities. The facility operates around the clock, and up to 7 days per week, as needed. Accelerator time is allocated in 1 day increments, with 24 hrs being sufficient for the measurement of 50-200 unknowns including spectrometer setup time for most isotopes. Conversion of the system from one isotope to another is generally $0.5-4$ hours, including tuning of the spectrometer.

Isotope ratio measurements are made possible by rapidly switching between isotopes, canceling time-dependent variations in source output and ion transmission rates. Measurement cycles are typically $300 \mathrm{~ms}$ in duration. Any given sample can be re-inserted for measurement multiple times, and measurements are usually made by repeatedly cycling through a group of unknowns along with appropriate blanks, standards, and controls.

The data acquisition system was developed in-house, and is optimized for high throughput with maximum flexibility in the measurement protocol. The system is being continually updated to allow greater flexibility, quality control, and longer periods of unattended operation. Data acquisition is automated, with minimal operator intervention required, including regular measurement of blanks, standards, and controls. Sample wheels hold up to 64 samples. Flexibility is maintained by allowing real-time modifications of the number or duration of measurements for individual or sets of samples. Actual measurement duration is controlled by the computer in real-time on a per sample basis, based on parameters such as required precision, number of counts acquired, minimum or maximum count rate, or maximum allowed time, as set by the operator. All data is recorded to disk during acquisition, and all measurements are permanently archived.

\section{Heavy Element Beamline}

Measurement of actinides at CAMS will require completion of a set of upgrades to the spectrometer, as well as additions to the existing data analysis and control systems. The primary hardware upgrades are a Heavy Element Beamline and a new ion source. The majority of the funding for the hardware portion of these upgrades 
is being provided through ongoing support from the USDOE Office of NonProliferation and National Security (NN-20).

The Heavy Element Beamline is required to provide transport of ions of mass 200-250 at sufficient energies to allow reasonable transmission, and some level of particle detection and identification. The $90^{\circ}$ analyzing magnets of the present high energy spectrometer (Figure 1) are not sufficient to bend ions of the required rigidity. The Heavy Ion Beamline will be installed on the $30^{\circ}$ port of the first switching magnet after the accelerator (see Figure 2).

The Heavy Element Beamline is being installed in 2 phases because of uncertainties in the emittance from the accelerator, and in the magnitude and nature of potential interferences. Phase I is presently in place and operational. The primary difference between the Phase I and Phase II beamlines (Figure 3) will be in the element used for velocity selection. For the Phase I beamline, velocity selection is made using an existing Wien filter. This filter is not expected to be sufficient to allow us to reach our ultimate level of sensitivity for measurement of actinides. The Phase II beamline will make use of a large Electrostatic Analyzer (ESA) having a significantly better velocity selection and improved detection sensitivity.

The Phase I beamline will be susceptible to ${ }^{238} \mathrm{U}$ and to other types of interferences from light isotopes at low charge states (discussed below). However, sensitivity is only expected to be a factor of 10-100 worse than the ultimate sensitivity we expect to achieve (and approaching the limits achieveable by other measurement techniques). Consequently, we expect to be able to perform most of our methods development on the Phase I beamline. As already stated, the results of this effort provide the basic data required for full optimization of the Phase II design.

Delivery of the ESA is expected in mid-1999. The specifications of the ESA are 4.4 $\mathrm{m}$ radius, $45^{\circ}$ deflection angle, and $50 \mathrm{kV} / \mathrm{cm}$ maximum field. An improved ion source (Figure 2) has already been installed and brought into routine operation. The injection line for this ion source will also include an ESA for velocity selection. The

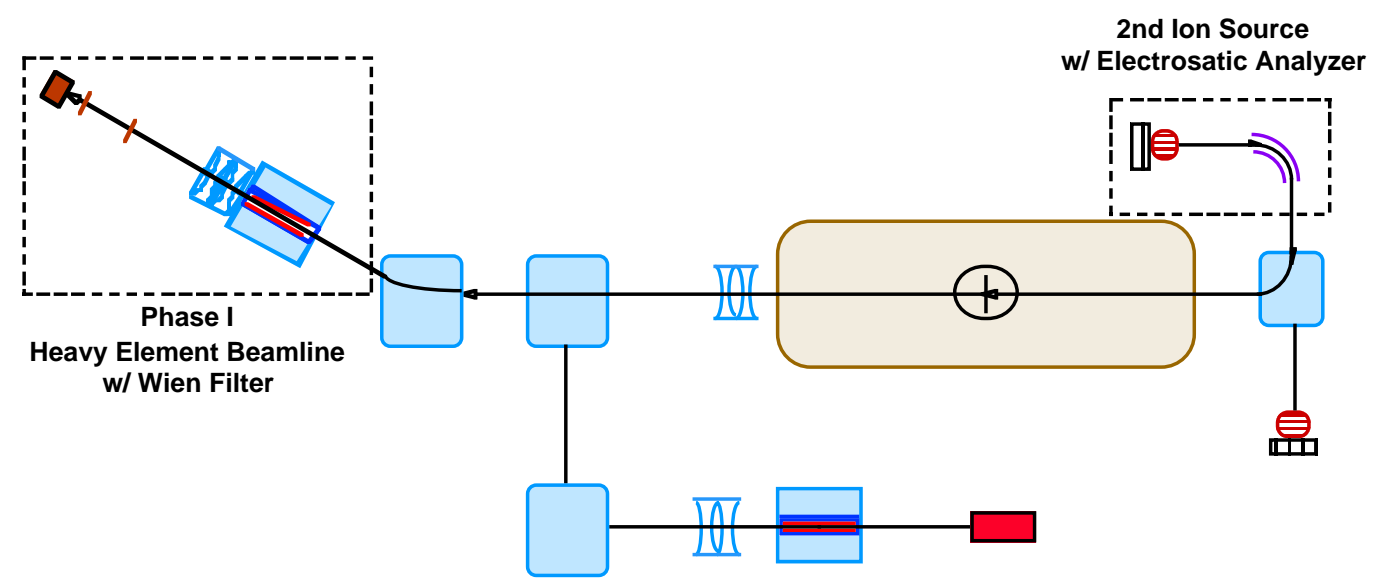

Figure 2. Phase I heavy ion beamline and second AMS ion source with electrostatic analyzer (ESA). 


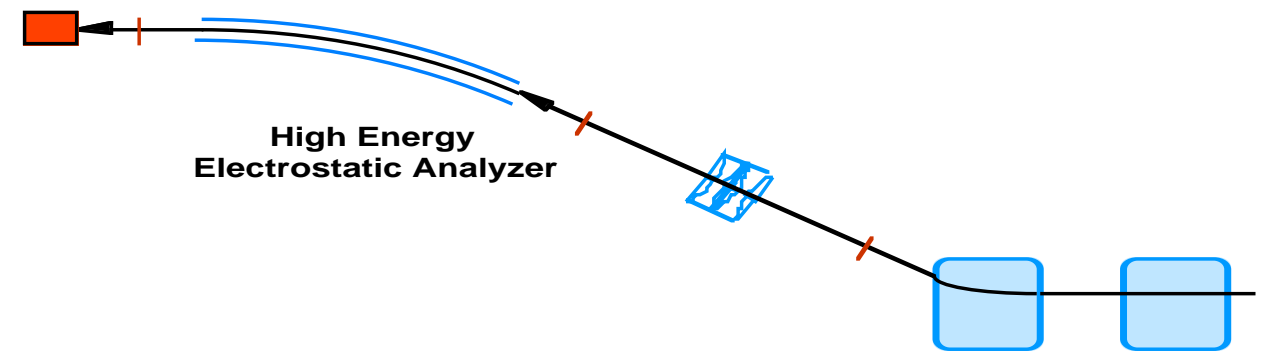

Figure 3. Phase II heavy ion beamline with high energy electrostatic analyzer (ESA).

ESA will serve to remove tails in the energy distribution of the ion beam and improve the overall mass selectivity.

FACTORS AFFECTING SENSITIVITY AND THROUGHPUT

\section{Detection efficiency}

A fundamental physical limit to the ultimate sensitivity of AMS is the total efficiency of the system-defined as the ratio of detected counts to total analyte atoms in the sample. For instance, the improvements in sensitivity for ICP-MS measurements over the last decade have come largely from improvements in detection efficiency. For mass spectrometric measurements, the total efficiency includes the chemical yield of the sample preparation chemistry, the fraction of the sample analyzed, the ionization efficiency, the efficiency for transport from the ion source to the detector, and the detection efficiency.

Chemical procedures for the purification and concentration of actinides are well developed and have high chemical yields, and for AMS measurements essentially all of the sample will be available for measurement. Total AMS efficiency will therefore be dominated by the ionization and beam transport efficiencies.

The ANU/Manchester group explored ionization efficiencies for actinides, and reported a total ionization efficiency for ${ }^{238} \mathrm{U} \rightarrow{ }^{238} \mathrm{U}^{16} \mathrm{O}^{-}$(including ion extraction) in the cesium sputter source of $0.3 \%$ (Fifield et al., 1996). Consequently, an ionization efficiency of $0.1-0.3 \%$ can reasonably be expected for most of the actinides.

For the ANU accelerator, ion transport efficiency for heavy ions is determined by a combination of stripping yield (defined as the fraction of the ions that leave the stripper in the selected charge state), and transmission of the ions through the accelerator. Stripping yields for actinides at the accelerator voltages of interest (3-9 $\mathrm{MV})$ are $\sim 0.5-10 \%$ depending on the charge state selected, the tandem voltage, and the type of stripping employed (gas or carbon foil). Measured yields in the ANU studies were significantly lower than this (0.1-1\%), largely because of poor transmission of the ions through their accelerator, which was designed mostly for applications in nuclear physics research. The CAMS accelerator was modified during 
its installation at LLNL to have a high acceptance, so that transmission efficiencies are near unity for lighter ions, and will be high (60-90\%) for actinides. The overall ion transport efficiency at CAMS will therefore be determined largely by the stripping yield.

In a first round of tests on the Phase I beamline, we observed a transmission for ${ }^{209} \mathrm{Bi}^{7+}\left({ }^{209} \mathrm{Bi}^{16} \mathrm{O}-\rightarrow{ }^{209} \mathrm{Bi}^{7+}, 7 \mathrm{MV}\right.$, gas stripping) of $2 \%$. Only a small difference in yield/transmission is expected between mass 209 and 239. With these values, the total system efficiency, and the expected efficiency limit for AMS sensitivity at CAMS, can be estimated. Using an ionization efficiency of $0.1 \%$, and the observed transmission efficiency for bismuth, a conservative estimate of the total system efficiency is $\sim 2 \times 10^{-5}$. This translates into $\sim 20$ detected counts for a sample containing $1 \times 10^{6}$ atoms ${ }^{239} \mathrm{Pu}$. The estimated efficiency limit to sensitivity is therefore $\sim 1 \times 10^{5}$ atoms.

Using an ionization efficiency of $0.3 \%$ and a stripping efficiency of $10 \%$, the total estimated efficiency will be $\sim 3 \times 10^{-4}$, or $\sim 300$ counts per $1 \times 10^{6}$ atoms. Analysis of two isotopes simultaneously (for instance, ${ }^{239} \mathrm{Pu}$ and ${ }^{240} \mathrm{Pu}$ ) would reduce the number of measured counts for a given isotope by a factor of two. For comparison, the sensitivity for ICP-MS, as reported by Chiappini et al. (1996), is around 110 counts per $1 \times 10^{6}$ atoms (assuming $1 \mathrm{~mL}$ sample, $180 \mathrm{~s}$ sampling time). The corresponding background noise was $360 \pm 110$ counts per $180 \mathrm{~s}$.

Interferences and contamination will clearly limit the sensitivity at some level, especially during the initial development work. What these estimates show, however, is that measurements will not be statistics limited. Just as importantly, statistics will be sufficiently high at these very low detection levels to allow detailed studies of the systematics of interferences and backgrounds, especially in evaluating sources of contamination in process blanks. These estimates also show that high statistics $(<1 \%)$ will be obtained for isotope dilution spikes using only a small fraction of the sample measurement cycle $(<5 \%)$, and with relatively low activity spikes $\left(<10^{10}\right.$ atoms of the spike isotope).

\section{Expected throughput}

For AMS measurement, the analyte will be dispersed in a small amount (0.1-1 $\mathrm{mg}$ ) of a solid carrier, for instance iron oxide. Maximum possible measurement times are determined by the time it takes to sputter the entire sample in the ion source. For $1 \mathrm{mg}$ samples, this is typically 15-60 minutes, depending on the sample material and operating parameters of the ion source. The operating conditions for measurements will be chosen to maximize count rate, given the constraints of ionization efficiency, sample performance, and total count rate in the detector. For routine analyses, measurements are generally limited to 15 minutes total measurement time or less (usually 3-5 repeats at 3-5 minutes each) per sample. For higher activity samples, or for samples where lower precision is required, measurement is automatically halted at a fixed number of counts. 
Total throughput for actinide analysis should be similar to that for other isotopes measured at CAMS. For a large set of very low activity unknowns $(<10 \mathrm{fg})$, where each is measured for 15 minutes, it will be possible to measure 3 unknowns (plus appropriate blanks and standards) per hour. This translates to roughly 60-70 unknowns in a 24 hour period when setup time is included. Allocation of 10 accelerator days per year ( $\sim 3 \%$ of total accelerator time) to actinides would provide a capacity for $500+$ unknowns at maximum sensitivity.

Routine measurement of samples with higher activities $\left(5 \times 10^{8}\right.$ atoms or greater) would require less than 5 minutes per sample, roughly tripling the throughput.

\section{${ }^{238} U$ interference}

Uranium represents a significant potential interference for AMS measurements just as it does for ICP-MS. However, the mechanism in AMS is somewhat different, and the potential for rejection of this interference using the spectrometer is much higher.

Uranium can remain in the sample following sample preparation, or can exist as a background contaminant in the ion source. Published results for the concentration and purification of plutonium from environmental samples for measurement by other analytical techniques show that ${ }^{238} \mathrm{U}$ levels $\sim 1 \times 10^{12}$ atoms per sample are readily attainable. Experience at CAMS with other background contaminants (such as copper and cobalt), combined with the lower relative natural abundance of uranium, indicate that background levels of uranium in the ion source should be negligible compared to this level.

${ }^{238} \mathrm{U}$ can be injected into the accelerator during ${ }^{239} \mathrm{Pu}$ measurement in two ways. First, and most implicit to the measurement, is via the low abundance oxygen isotope ${ }^{17} \mathrm{O}\left(0.04 \%\right.$ natural abundance). Plutonium will be injected as ${ }^{239} \mathrm{Pu}^{16} \mathrm{O}-$, at mass $255 .{ }^{238} \mathrm{U}^{17} \mathrm{O}^{-}$is a molecular isobar at this mass that will also be injected. In this case, the ${ }^{238} \mathrm{U}^{17} \mathrm{O}^{-} /{ }^{238} \mathrm{U}^{16} \mathrm{O}^{-}$ratio is fixed by the ${ }^{17} \mathrm{O}$ abundance. At present, this is not expected to be the dominant mechanism.

${ }^{238} \mathrm{U}$ may also be injected as ${ }^{238} \mathrm{U}^{16} \mathrm{O}^{-}$. In this case, some ${ }^{238} \mathrm{U}^{16} \mathrm{O}^{-}$ions (mass 254 ) on the high side of the energy distribution (the ${ }^{238} \mathrm{U}^{16} \mathrm{O}^{-}$"tail") will have the correct rigidity to pass through the injection slits. Scattering or other processes could also add to the intensity on this tail. The low energy ESA on the second ion source (Figure 2) will provide ion selection by velocity, suppressing the tails of the energy distribution. Based on optics calculations and preliminary measurements, total rejection of ${ }^{238} \mathrm{U}$ by the CAMS spectrometer will at least be $\sim 1 \times 10^{-6}$ (conservative), and potentially below $1 \times 10^{-8}$ (optimistic). Therefore, the expected uranium background for ${ }^{239} \mathrm{Pu}$ measurements should fall between $<1-10 \times 10^{5}$ atoms. Uranium interference for ${ }^{240} \mathrm{Pu}$ measurements is expected at a similar level while for other actinides (e.g., ${ }^{237} \mathrm{~Np},{ }^{242} \mathrm{Pu},{ }^{244} \mathrm{Pu}$, and ${ }^{233} \mathrm{U}$ ) this interference should be significantly lower. 


\section{Lighter-Ion Interferences}

As discussed in the preceding section, realistic estimates about the sources, intensity, and rejection of interference from uranium can be made with relatively limited data.

A different source of interference, with a much larger uncertainty, can come from isotopes of much lower mass, but which have the same rigidity and velocity as the isotope being measured. These are therefore transported through the spectrometer and into the detector with the analyte. This can happen either through direct processes, when the spectrometer settings exactly match the rigidity/velocity of the interference beam, or through scattering and tails of distributions. The interference can come in two forms as well: simply causing too much count rate in the detector to allow measurements; or by having exactly the same response in the detector as the analyte and being counted incorrectly.

Empirically, lighter-ion interferences are not a problem in the ANU spectrometer, either as high count rates or as measurement backgrounds (except in one case, with sub-optimum spectrometer parameters). The ANU facility has somewhat better resolution than CAMS in both the low energy and high energy spectrometers. In addition, transmission through the ANU accelerator is fairly low, which may also have the effect of improving resolution. However, the ANU spectrometer has no electrostatic filtering elements in either the low or high energy spectrometers. Electrostatic analyzers (ESA) designed specifically for actinide measurements, are planned for both the low and high energy spectrometers at CAMS, and will significantly suppress the number and intensity of lighter-ion interferences.

We also suspect that the presence of lighter-ion interferences may be somewhat suppressed at these higher mass numbers than for isotopes in the middle of the periodic table. The reason for this is the large difference in mass number between the actinides and elements that have significant natural abundance. Potential interferences would have to be injected into the accelerator as large, polyatomic ions. At the same time, this reduces the probabilities of ion formation and transport through the spectrometer.

If lighter-ion interferences are encountered, we will have a large number of options available. These interferences vary significantly with a number of parameters, primarily charge state and sample matrix and, in general, the interfering element(s) will be chemically different from the analyte, and therefore amenable to cleanup. This expectation is supported by our experience with other isotopes (e.g., $\left.{ }^{99} \mathrm{Tc}\right)$. 


\section{SAMPLE PREPARATION}

\section{Anticipated protocol}

Based on the ANU work, and our own experience with preparing other elements for AMS measurements, the sample preparation required for AMS is expected to be significantly simpler and shorter than for other low-level measurement techniques. Sample digestion, preconcentration of the analyte, and initial purification will be essentially identical to that of other techniques. Some additional steps may be needed for further removal of uranium or lighter-ion interferences, but in general AMS will be less susceptible to these interferences (for instance, AMS will be 1-3 orders of magnitude less sensitive to uranium interference than ICP-MS). Trace impurities such as salts or organics will not affect AMS results. Following purification, it is expected that a simple co-precipitation with a carrier matrix, such as iron hydroxide, followed by heating in a muffle furnace, will be sufficient to produce optimal sample for AMS measurements. It is worth noting that many of the published procedures for other analytical methods also include similar coprecipitation steps as just one of many steps in a larger procedure.

\section{Process blanks - strategies for sample processing}

For measurements at extremely low-levels, process blanks will become a serious problem, and reduction of process blanks will very likely dominate the sample preparation complexity, expense, and throughput, as well as the ultimate sensitivity obtainable by AMS.

Process blank refers to the level of analyte added to the sample as a contaminant during the sample preparation. Many of the isotopes we are targeting are now common contaminants in the environment at the levels of interest, and will potentially be introduced into samples through process reagents, exposure to the atmosphere in the laboratory, and cross-contamination from other samples. Consequently, the ability to obtain low and reproducible blanks will be a major limitation in truly defining the lowest possible levels of detection by AMS. We will develop rigorous sample handling and preparative protocols based on an automated fluid management and closed loop separation techniques. Employing the prescribed separation technology will help optimize conditions inherently necessary to obtain low and reproducible blanks along with high and reproducible analytical yields, and provide for potential savings in the cost of routine analyses through significant reductions in labor, time, reagents and glassware.

\section{CONCLUSIONS}

There appears to be a sound scientific basis for the development of a low-level actinide AMS detection capability at CAMS. AMS is a proven technology for the quantitative measurement of low-levels of ${ }^{239} \mathrm{Pu}$ with detection limits and freedom from interferences that are superior to that of ICP-MS, and with similar or better 
sensitivity than FTA and/or RIMS. These gains in sensitivity add real scientific value to the interpretation of data for a range of applications-including bioassay programs.

Historically, AMS has been considered an expensive technique applied only where there was a need for several orders of magnitude improvement in sensitivity. At CAMS, because of the high throughput and robust nature of the instrument, actinide measurements would only use a small fraction of the total capacity of the facility. This dilutes the expected per sample analysis cost. By comparison, optimum sensitivity for comparable ICP-MS measurements could only be achieved on a dedicated instrument using a significant fraction of a full time technician. Consequently, AMS throughput and cost effectiveness are expected to be much higher than TIMS, FTA, or RIMS, and competitive or better than ICP-MS. Moreover, ICP-MS systems have not yet been fully proven for the reliable measurement of plutonium isotopes and/or other actinides at the lower level detection limits claimed by the instrument manufacturers. We believe the ability to reliably determine plutonium isotopes and other actinides at very low-levels using AMS technology, combined with the high-throughput of the CAMS spectrometer, will provide for a valuable and viable resource for DOE and the scientific community worldwide.

\section{ACKNOWLEDGMENTS}

Work preformed under the auspices of the U.S. Department of Energy at the Lawrence Livermore National Laboratory under contract W-7405-Eng-48.

\section{REFERENCES AND SELECTED BIBLIOGRAPHY}

J. S. Alvarado, M. D. Erickson. Determination of long-lived radioisotopes using electrothermal vaporization-inductively coupled plasma mass spectrometry. J. Anal. At. Spec. 11 (1996) 923.

J. S. Alvarado, T. J. Neal, L. L. Smith, M. D. Erickson. Microwave dissolution of plant tissue and the subsequent determination of trace lanthanide and actinide elements by inductively coupled plasma-mass spectrometry. Anal. Chim. Acta $322(1996) 11$

E. Bailey, A. J. Kemp, K. V. Ragnarsdottir. Determination of uranium and thorium in basalts and uranium in aqueous solution by inductively coupled plasma mass spectrometry. J. Anal. A.t Spec. 8 (1993) 551 
M. S. Baxter, S. W. Fowler, P. P. Povinec. Observations on plutonium in the oceans. App. Rad. Isot. 11 (1995) 1213

K. O. Buesseler, J. E. Halverson. The mass spectrometric determination of fallout ${ }^{239} \mathrm{Pu}$ and ${ }^{240} \mathrm{Pu}$ in marine samples. J. Envir. Rad. 5 (1987) 425

R. Chiappini, J.-M. Taillade, S. Brébion. Development of a high-sensitivity inductively couple plasma mass spectrometer for actinide measurement in the femtogram range. J. Anal. At. Spec. 11 (1996) 497

J. S. Crain (1996). Application of inductively coupled plasma-mass spectrometry. Spec. 11, 30

J. S. Crain, J. Alvarado. Hydride interference on the determination of minor actinide isotopes by inductively coupled plasma mass spectrometry. J. Anal. At. Spec. 9 (1994) 1223

J. S. Crain, L. L. Smith, J. S. Yaeger, J. A. Alvarado. Determination of long-lived actinides in soil leachates by inductively coupled plasma-mass spectrometry. J. Rad. Nucl. Chem. 194 (1995) 133

J. P. Day, private communication (1998).

C. Davis, I. D. Proctor, J. R. Southon, M. W. Caffee, D. W. Heikinen, M. L. Roberts, T. L. Moore, K. W. Turteltaub, D. E. Nelson, D. H. Loyd, J. S. Vogel. LLNL/UC AMS facility and research program. Nucl. Inst. and Meth. 52 (1990) 269

K. Eberhardt, N. Erdmann, H. Funk, G. Herrmann, S. Köhler, A. Nähler, G. Passler, N. Trautmann, F.-J. Urban. Chemical separation of plutonium from air filters and preparation of filaments for resonance ionization mass spectroscopy. AIP Conf . Proc. 329 (1994) 503

N. Erdmann, F. Albus, R. Deißenberger, K. Eberhardt, H. Funk, H.-U. Hasse, G. Herrmann, G. Huber, H.-J. Kluge, S. Köhler, M. Nunnemann, G. Passler, N. Trautmann, F.-J. Urban. Resonance ionization mass spectroscopy for trace analysis of plutonium. AIP Conf. Proc. 329 (1994) 507

N. Erdmann, G. Hermann, G. Huber, S. Köhler, J. V. Kratz, A. Mansel, M. Nunnemann, G. passler, N. Trautmann, A. Turchin, A. Waldek. Resonance ionization mass spectroscopy for trace determination of plutonium in environmental samples. Fres. J. Anal. Chem. 359 (1997) 378

L. K. Fifield, A. P. Clacher, K. Morris, S. J. King, R. G. Cresswell, J. P. Day, F. R. Livens. Accelerator mass spectrometry of the planetary elements. Nucl. Inst. and Meth. B 123 (1997), 400 
L. K. Fifield, R. G. Cresswell, M. L. di Tada, T. R. Ophel, J. P. Day, A. P. Clacher, S. J. King, N. D. Priest. Accelerator mass spectrometry of the plutonium isotopes. Nucl. Inst. and Meth. B 117 (1996), 295

L. Johansson, E. Holm. Determination of trace-amounts ${ }^{239} \mathrm{Pu}$ using fission track analysis, Nucl. Inst. Meth. Phys. Res. A 376 (1996) 242

Z. Karpas, L. Halicz, J. Roiz, R. Marko, E. Karorza, A. Lorber, Z. Goldbart. Inductively coupled plasma mass spectrometry as a simple, rapid, and inexpensive method for determination of uranium in urine and fresh water: comparison with LIF. Health Phys. 71 (1996) 6

W. Kerl, J. S. Becker, H.-J. Dietze, W. Dannecker. Isotopic and ultratrace analysis of uranium by double-focusing sector field ICP mass spectrometry. Fres. J. Anal. Chem. 359 (1997) 407

C. Kim, R. Seki, S. Morita, S. Yamasaki, A. Stumura, Y. Takaku, Y. Igarashi, M. Yamamoto. Application of a high-resolution inductively coupled plasma mass spectrometer to the measurement of long-lived radionuclides. J. Anal. At. Spec. 6 (1991) 205

M.P. Krahenbul, D.M. Slaughter. Improving process methology for measuring plutonium burden in human urine using fission track analysis, J. Radanal. Nucl. Chem. 230(1-2) (1998) 153

S.C. Lee, J. M. Robin Hutchinson, K. G. W. Inn, M. Thein. An intercomparison study of ${ }^{237} \mathrm{~Np}$ determination in artificial urine samples. Health Phys. 68 (1995) 350

A. Lorber, Z. Karpas, L. Halicz. Flow injection method for determination of uranium in urine and serum by inductively coupled plasma mass spectrometry. Anal. Chim. Acta 334 (1996) 295

A. McCormick. Thermal-ionization mass spectrometry for small sample analysis of uranium and plutonium. Appl. Rad. Isot. 43 (1992) 271

L. Moens, N. Jakubowski. Double-focussing mass spectrometry in ICPMS. Anal. Chem. 70 (1998) A251.

N. Momoshima, H. Kakiuchi, Y. Maeda, E. Hirai, T. Ono. Identification of the contamination source of plutonium in environmental samples with isotopic ratios determined by inductively coupled plasma mass spectrometry and alphaspectrometry. J. Rad. Nucl. Chem. 221 (1997) 213 
A. Moorthy, C.J. Schopfer, S. Banerjee. Plutonium from atmospheric weapons testing: fission track analysis of urine samples, Anal. Chem. 60(14) (1988) 857A

J. M. Barrero Moreno, M. Betti, J. I. Garcia Alonso. Determination of neptunium and plutonium in the presence of high concentrations of uranium by ion chromatography-inductively coupled plasma mass spectrometry. J. Anal. At. Spec. 12 (1997) 355

R. E. Perrin, G. W. Knobeloch, V. M. Armijo, D. W. Efurd. Isotopic analysis of nanogram quantities of plutonium by using a SID ionization source. Int. J. Mass. Spec. Ion.Proc . 64 (1985) 17

M. L. Roberts, G. S. Bench, T. A. Brown, M. W. Caffee, R. C. Finkel, S. P. H. T. Freeman, L. J. Hainsworth, M. Kashgarian, J. E. McAninch, I. D. Proctor, J. R. Southon, J. S. Vogel. The LLNL AMS facility. Nucl. Inst. and Meth. B 123 (1996) 57

P. Roth, E. Werner, I. Wendler, P. Schramel. Application of ICP-MS for the assessment of thorium excretion in urine. Appl. Rad. Isot. 47 (1996) 1055

W. Ruster, F. Ames, H.-J. Kluge, E.-W. Otten, D. Rehklau, F. Scheerer, G. Herrmann, C. Mühleck, J. Riegel, H. Rimke, P. Sattelberger, N. Trautmann. A resonance ionization mass spectrometer as an analytical instrument for trace analysis. Nucl. Inst. Meth. A281 (1989) 546

R. D. Scott, M. S. Baxter, A. S. Hursthouse, K. McKay, K. Sampson, J. Toole. Geological and nuclear applications of inductively coupled plasma mass spectrometry. Anal. Proc. 28 (1991) 382

S. Sumiya, S. Morita, K. Tobita, M. Kurabayashi. Determination of technetium-99 and neptunium-237 in environmental samples by inductively coupled plasma mass spectrometry. J. Rad. Nucl. Chem. 177 (1994) 149

L. C. Sun, A. R. Moorthy, E. Kaplan, J. W. Baum, C. B. Meinhold. Assessment of plutonium exposures in Rongelap and Utirik populations by fission track analysis of urine. App Rad Isot 11 (1995) 1259

R. N. Taylor, I. W. Croudace, P. E. Warwick, S. J. Dee. Precise and rapid determination of ${ }^{238} \mathrm{U} /{ }^{235} \mathrm{U}$ and uranium concentration in soil samples using thermal ionisation mass spectrometry. Chem. Geo. 144 (1998) 73

F.-J. Urban, R. Deißenberger, G. Herrmann, S. Köhler, J. Riegel, N. Trautmann, H. Wendeler, F. Albus, F. Ames, H.-J. Kluge, F. Scheerer. Resonance ionization mass spectroscopy of plutonium with a reflectron time-of-flight mass spectrometer. Inst. Phys. Conf. Ser. 128 (1992) 233 
J. S. Vogel, K. W. Turteltaub, R. Finkel, D. E. Nelson. Accelerator mass spectrometry: isotope quantification at attomole sensitivity. Anal. Chem. 67 (1995) 353A

D. Wollenweber, H. Wildner, G. Wünsch. Uranium determination in process chemicals: on the way to sub-pg/g concentrations. Fres. J. Anal. 359 (1997) 414

M.E. Wreen, N.P. Singh, Y.H. Xue. Urinary Excretion of ${ }^{239} \mathrm{Pu}$ by the general population: measurement technique and results. Radiat. Protection Dosim. 53(1-4) (1994) 81 


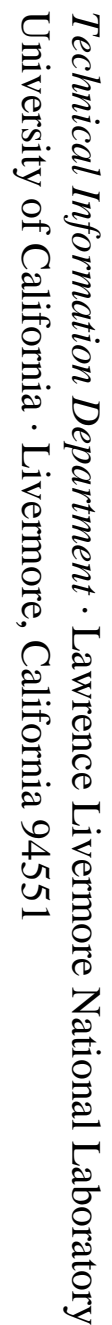

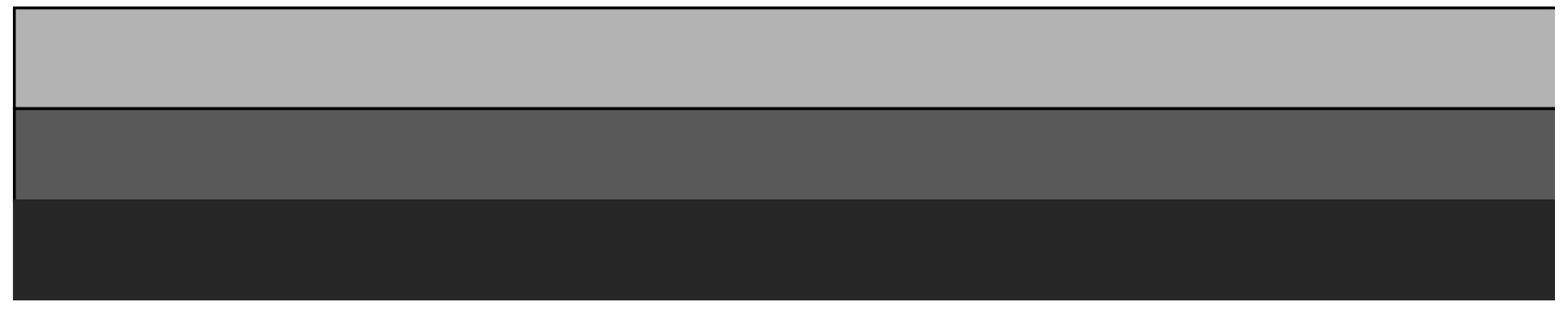

